\title{
A large-scale viability assessment of the potato cryobank at the International Potato Center (CIP)
}

\author{
Rainer Vollmer $^{1}$ (D) Rosalva Villagaray ${ }^{1} \cdot$ José Cárdenas $^{1} \cdot$ Mario Castro $^{1} \cdot$ \\ Oswaldo Chávez ${ }^{1} \cdot$ Noelle L. Anglin ${ }^{1} \cdot$ David Ellis $^{1}$
}

Received: 11 February 2017 / Accepted: 28 July 2017 /Published online: 24 August 2017 / Editor: Barbara Reed

(C) The Author(s) 2017. This article is an open access publication

\section{Introduction}

The International Potato Center (CIP) in Lima, Peru, maintains the global in-trust collection of cultivated potato. The material from this collection is distributed worldwide on request for research, breeding, and education under the auspices of the International Treaty for Plant Genetic Resources for Food and Agriculture (ITPGRFA, http://www.fao.org/planttreaty/en/) (FAO 2009). The 4388 accessions in this collection are maintained in vitro to ensure that once cleaned of viruses, the germplasm remains virus free and can move freely across international borders without introducing disease(s) to other countries. While in vitro maintenance safeguards the material from infection, it requires a large number of resources to maintain an in vitro collection of this size. One way to reduce the cost of maintenance while still conserving the germplasm is to back up the collection in a cryobank. In fact, cryopreserved material could be the primary storage for some accessions that are genetically unique, but rarely requested. The shoot tips can be thawed from liquid nitrogen and regenerated into a plantlet when needed for research or distribution purposes.

Cryopreservation protocols applicable to dozens of crops have been developed during the last two decades and many plant genetic research institutes have cryobanks that conserve hundreds or up to thousands of accessions (Pritchard 2016). However, throughput rates for large collections, quality standards, number of stored samples and repetitions, minimum viability criteria, inter-vial variation, backup storage strategies,

Rainer Vollmer

r.vollmer@cgiar.org

1 International Potato Center, Lima, Peru and effective linkage with other genebank programs (for example, genetic identity testing) vary widely between species and cryobanks. These variables are often dependent on resources, staffing, and other priorities in the genebanks. At $\mathrm{CIP}$, clear and strict quality standards were implemented in 2013, defining many of the characteristics described above (Vollmer et al. 2016). Despite this, the development of protocols applicable to large-scale cryopreservation of diverse collections, even within a single crop, can be a time-consuming, evolving, and a continuous process.

The pioneers of potato cryopreservation published their first protocols about 35-40 yr ago (Bajaj 1978, 1981; Grout and Henshaw 1978; Towill 1981, 1983, 1984). Although the initial methods permitted successful cryopreservation of some potato genotypes, the development and adaptation of these protocols to high-throughput cryopreservation of diverse potato collections needed further refinement and simplification for routine use. Researchers at the Leibniz Institute DSMZ (German Collection of Microorganisms and Cell Cultures) refined the protocols in the mid-1990s, so a cryopreservation method could be successfully applied to hundreds of potato genotypes (Schäfer-Menuhr et al. 1994, 1997). Recently, researchers have published other promising methods for potato cryopreservation, such as the D and V cryoplate. In these methods, shoot tips are "stuck" on special aluminum plates with uniform wells using sodium alginate to facilitate uniform sample handling, reduced risk of damage, and reduced loss of shoot tips (Yamamoto et al. 2015; Valle et al. 2017).

At CIP, potato cryopreservation was initiated in the late 1990s (Golmirzaie and Panta 2000) by a protocol developed for Musa species (Panis et al. 2005) and the protocol has been continuously modified and improved (Panta et al. 2015; Vollmer et al. 2016). In 2013, CIP's cryobank established a clear and strict quality management system (QMS), started to build a cryobank for the future with defined quality standards 
(Vollmer et al. 2016), and began actively adding on average 400 accessions per year into the cryobank. This paper describes the current status of CIP's cryobank, analysis by potato species/subspecies (taxonomy based on Hawkes 1990), ploidy level, and country of origin to determine factors that affect the success rate, and the progress made over the last few yr. It also includes the results of a large-scale viability reassessment of 857 potato accessions, conserved for 1-2 yr in liquid nitrogen, and an assessment of the influence of the human factor on the survival and recovery rates of potato accessions cryopreserved with the droplet vitrification method (Sakai et al. 1990).

\section{Materials and Methods}

Propagation of plant material In vitro plantlets were subcultured into $\mathrm{GA}_{7}$ Magenta ${ }^{\mathrm{TM}}$ boxes (Química Service SRL, Lima, Peru) every 3 wk onto semi-solid-modified MS medium (Murashige and Skoog 1962) (Medium Type: MSP09, Caisson Laboratories, East Smithfield, PA) supplemented with $25 \mathrm{~g} \mathrm{~L}^{-1}$ of sucrose (S8501, Sigma-Aldrich®, St. Louis, MO) and $3.0 \mathrm{~g} \mathrm{~L}^{-1}$ of Phytagel ${ }^{\mathrm{TM}}$ (P8169, SigmaAldrich $\AA)$. The $\mathrm{pH}$ was adjusted to $5.6 \pm 0.02$ with $\mathrm{NaOH}$ ( $2 \mathrm{M})$ and $\mathrm{HCl}(2 \mathrm{M})$. The culture media was autoclaved at $121^{\circ} \mathrm{C}$ for $20 \mathrm{~min}$. Plants were incubated at $18-22^{\circ} \mathrm{C}$ with a 16-h photoperiod and light intensity of 80-100 $\mathrm{mmol} \mathrm{m}^{-2} \mathrm{~s}^{-1}$ provided by cool day light fluorescent tubes (TL-D 36W/865, Philips Lightning S.A., Miraflores, Lima, Perú). For the final transfer, terminal buds were subcultured on the same culture medium in $2.5 \mathrm{~cm}$ deep Petri dishes (70 buds per Petri dish) and incubated for $2-3 \mathrm{wk}$ at $6-8^{\circ} \mathrm{C}$ at low light intensity (15-25 $\mu \mathrm{mol} \mathrm{m} \mathrm{m}^{-2} \mathrm{~s}^{-1}$ ), with a photoperiod of $16 \mathrm{~h}$.

Excision of shoot tips Shoot tips were excised from 2- to 3wk-old cold-acclimated in vitro grown plantlets $\left(6-8^{\circ} \mathrm{C}\right.$, see description of final transfer in previous section). Excised shoot tips contained 3-4 leaf primordia with a length of $0.8-1.2 \mathrm{~mm}$ and a width of $0.4-0.7 \mathrm{~mm}$. A total of $130-150$ shoot tips were excised for each accession.

Cryoprotection Shoot tips were treated for $20 \mathrm{~min}$ with loading solution (LS) [liquid-modified MS medium (Caisson Laboratories, MSP09) containing 2.0 M glycerol (G5516, Sigma-Aldrich $($ ) and $0.4 \mathrm{M}$ sucrose, adjusted to $\mathrm{pH} 5.8$ ] at $20-24^{\circ} \mathrm{C}$, followed by treatment with plant vitrification solution 2 (PVS2) [liquid-modified MS medium containing 3.28 M glycerol, 2.42 M ethylene glycol (324558, SigmaAldrich $®), 1.9 \mathrm{M}$ dimethylsulfoxide (DMSO) (D4540, Sigma-Aldrich $\left.{ }^{\circledR}\right)$, and $0.4 \mathrm{M}$ sucrose, adjusted to $\left.\mathrm{pH} 5.8\right]$ for $50 \mathrm{~min}$ on ice $\left(0^{\circ} \mathrm{C}\right)$.
Freezing in liquid nitrogen Just prior to the end of the PVS2 treatment, 10 shoot tips were placed in a $10-\mu \mathrm{L}$ pre-chilled $\left(0^{\circ} \mathrm{C}\right)$ droplet of PVS2 on a sterile aluminum foil strip $(5 \times 20 \mathrm{~mm})$ (Boardwalk ${ }^{\circledR}$ BWK 7136, Essendant Co., Deerfield, IL) and quickly plunged into liquid nitrogen (LN) $\left(-196^{\circ} \mathrm{C}\right)$ immediately after a $50-$ min exposure to PVS2. The frozen aluminum foil strip was transferred into a $1.8-\mathrm{mL}$ cryovial (internal thread Nunc ${ }^{\mathrm{TM}}$, Thermo Fisher Scientific ${ }^{\mathrm{TM}}$, Waltham, MA) under LN so that each cryovial contained 10 shoot tips. For routine cryopreservation, 130 150 shoot tips (13-15 cryotubes) per accession were processed. After a minimum of $24 \mathrm{~h}$ in LN, a sample of 30 shoot tips (three vials) were thawed to obtain an initial survival and recovery rate.

Thawing Aluminum foil strips with 10 frozen shoot tips were quickly thawed by removing the foil strip from the cryovial and submerging it directly into rewarming solution (RS) (liquid-modified MS medium containing 1.2 M sucrose, adjusted to $\mathrm{pH}$ 5.8). The shoot tips were rewarmed in $\mathrm{RS}$ for $20 \mathrm{~min}$ at $20-24^{\circ} \mathrm{C}$.

Recovery Shoot tips were recovered in $1.5 \mathrm{~cm}$ deep Petri dishes on semi-solid recovery medium consisting of a modified MS medium, supplemented with $0.4 \mathrm{mg} \mathrm{L}^{-1}$ kinetin (K3378, Sigma-Aldrich®), $0.1 \mathrm{mg} \mathrm{L}^{-1}$ gibberellic acid (G7645, Sigma-Aldrich®), $20 \mathrm{~mL} \mathrm{~L}^{-1}$ coconut water (C5915, Sigma-Aldrich®), 0.3 M sucrose, and $2.8 \mathrm{~g} \mathrm{~L}^{-1}$ Phytagel $^{\mathrm{TM}}$ (P8169, Sigma-Aldrich®). The $\mathrm{pH}$ was adjusted to $5.6 \pm 0.02$ with $\mathrm{NaOH}(2 \mathrm{M})$ and $\mathrm{HCl}(2 \mathrm{M})$. The culture medium was autoclaved for $20 \mathrm{~min}$ at $121^{\circ} \mathrm{C}$. Filter-sterilized kinetin, gibberellic acid, and coconut water stock solutions were added to the culture medium after autoclaving. Three pieces of filter paper (grade 2, brand: Whatman $\AA$, SigmaAldrich $®)$, each containing the 10 shoot tips from a single vial were placed in each Petri dish. Shoot tips were incubated for $3 \mathrm{~d}$ in darkness at $18-22^{\circ} \mathrm{C}$ by wrapping the Petri dishes with aluminum foil, followed by $3 \mathrm{~d}$ on modified MS culture media of the same composition, but with decreased sucrose concentrations of 0.1 and $0.2 \mathrm{M}$ (both in darkness). After $9 \mathrm{~d}$ in darkness, shoot tips were removed from the filter paper and placed directly onto culture medium with the same composition as the recovery medium, but containing $0.07 \mathrm{M}$ sucrose, and incubated for $4 \mathrm{~d}$ under diffuse light at $18-22^{\circ} \mathrm{C}$ with a 16 $\mathrm{h}$ photoperiod (covering the top of the Petri dishes with a sheet of aluminum foil), followed by normal light conditions (80$100 \mu \mathrm{mol} \mathrm{m} \mathrm{s}^{-2}$ ). After $30 \mathrm{~d}$, surviving and recovered shoot tips were transferred individually into $13 \times 100 \mathrm{~mm}$ test tubes, containing the same medium $(0.07 \mathrm{M}$ sucrose). Recovered samples without root formation were cut slightly at the base before transferring to the test tubes. 
Viability assessment Viability was assessed 30 and $60 \mathrm{~d}$ after thawing. After $60 \mathrm{~d}$, a shoot was classified as recovered, if it had developed into a complete and morphologically normal looking in vitro plant (elongated stem, functional apex, leaves, and roots). If the samples did not develop into complete in vitro plants, the samples were recorded as survived, but not recovered. Shoot tips that developed into deformed plants showed only leaf formation or had signs of hyper-hydration (vitrification) were classified as survived, but not recovered.

Transfer to the cryobank and safety backup tank Based on the observed recovery rate after $60 \mathrm{~d}$, previously determined QMS standards governed whether an accession was transferred to the cryobank, if a second attempt at cryopreservation (cryorun) was required, or if the current cryorun was discarded. For accessions that had a recovery rate of $30 \%$ or higher, one single cryorun was stored in the cryobank with two vials set aside in a separate cryotank for a safety backup. For accessions that showed a recovery rate of $20-30 \%$ in the first cryorun, an additional independent second cryorun was performed and both runs were stored if both runs had recovery rates $>20 \%$. Those cryoruns with 20-30\% recovery rates had four vials stored as a safety backup. Accessions with less than $20 \%$ recovery rates were discarded and not transferred to the cryobank.

Ploidy determination The ploidy levels of the potato accessions were determined using flow cytometry utilizing a BD Accuri ${ }^{\mathrm{TM}}$ C6 flow cytometer (BD Biosciences, San Jose, CA). For sample preparation, 50-60 mg of young leaf tissue was cut in a Petri dish containing $250 \mu \mathrm{L}$ of LB01 buffer. LB01 buffer was prepared as described by Doležel et al. (1989). Additionally, $250 \mu \mathrm{L}$ of LB01 buffer was added to the suspension and incubated for $2 \mathrm{~min}$ at $20-24^{\circ} \mathrm{C}$, followed by filtering through a $50-\mu \mathrm{m}$ CellTrics ${ }^{\circledR}$ filter (Sysmex Corp, Lincolnshire, IL). Staining of nuclei was done with $50 \mu \mathrm{g} \mathrm{mL}^{-1}$ propidium iodide (Calbiochem, San Diego, CA), staining of double-stranded RNA was avoided by adding $50 \mu \mathrm{g} \mathrm{mL}^{-1}$ of RNase (R6513, Sigma-Aldrich ${ }^{\circledR}$ ). After an additional incubation period of $2 \mathrm{~min}$ in darkness, samples were analyzed by flow cytometry at medium run speed (with 1000 and 10,000 events for the FL2-H and FSC-H threshold, respectively). Each run had a duration of 2 min with a minimum of 400 events per $\mathrm{G} 0 / \mathrm{G} 1$ peak. Results were interpreted by comparison with reference standards of known potato ploidy levels. Manual chromosome counts of root tips were performed as described by Orillo and Bonierbale (2009) when required.

Data analysis Data was analyzed with a one-way ANOVA test $(p<0.05)$ and the Tukey multiple comparison test $(p<0.05)$ using the MINITAB 17.3.1 and EXCEL 2016 software. Accessions that did not fulfill the minimum reassessment criteria ( 8 accessions), or had pending viability reassessment results ( 4 accessions) were excluded from all analyses (Table 1). The Solanum $\times$ ajanhuiri, $S$. $\times$ curtilobum, and $S$. ×juzepczukii species were excluded from the statistical analyses for the inter-specific comparison, as these groups contained only $2-11$ accessions. All species were included (sample size per group 109 to 575) for the comparison of survival and recovery rates between years 2013-2016. For the evaluation of the effect of ploidy level on survival and recovery rates, 1327 of 1533 potato accessions with confirmed ploidy levels $(2 \times, 3 \times, 4 \times)$ were included. However, the pentaploid species $(S . \times$ curtilobum $)$ was excluded from statistical analysis because of a low sample number $(n=2)$. The variance of survival and recovery rates of the accessions based on country of origin was analyzed and countries with a low sample size were excluded from the analyses, e.g., Bangladesh $(n=2)$, Bhutan $(n=1)$, Costa Rica $(n=1)$, Guatemala $(n=8)$, Mexico $(n=6)$, Netherlands $(n=1)$, and Russia $(n=9)$ (Table 4). The success rate for cryopreservation was expressed as a ratio between successfully cryopreserved and totally processed accessions (Fig. 1).

Viability reassessment The viability of the accessions cryopreserved in 2014 and 2015 was assessed after a period of 1$2 \mathrm{yr}$ in LN. The recovery rates from this reassessment were compared with the average recovery rates of the three original cryovials ( 30 shoot tips) thawed $\sim 24 \mathrm{~h}$ after freezing for the baseline viability (referred to as the "original viability"). The reassessment consisted of removing an additional cryopreserved vial for each accession from the cryobank, thawing,

Table 1. The number of originally processed accessions, number of accessions that did not pass the viability reassessment check, and number of accessions with pending viability reassessment

\begin{tabular}{|c|c|c|c|c|c|}
\hline \multirow[t]{2}{*}{ Description } & \multicolumn{4}{|c|}{ Year of cryopreservation } & \multirow[b]{2}{*}{ Total } \\
\hline & 2013 & 2014 & 2015 & 2016 & \\
\hline $\begin{array}{l}\text { Number of cryopreserved } \\
\text { accessions (originally) }\end{array}$ & 113 & 415 & 442 & 575 & 1545 \\
\hline $\begin{array}{l}\text { Number of accessions that } \\
\text { did not pass the } \\
\text { viability reassessment }\end{array}$ & 4 & 4 & 0 & $-^{\mathrm{c}}$ & 8 \\
\hline $\begin{array}{l}\text { Number of accessions } \\
\text { with pending viability } \\
\text { reassessment }{ }^{\mathrm{a}}\end{array}$ & 0 & 1 & 3 & $-^{\mathrm{c}}$ & 4 \\
\hline Total $^{\mathrm{b}}$ & 109 & 410 & 439 & 575 & 1533 \\
\hline
\end{tabular}

${ }^{a}$ The viability reassessment of 4 accessions, cryopreserved in 2014/2015 accessions is still pending

${ }^{\mathrm{b}}$ Total $=$ number of cryopreserved accessions - number of accessions that did not pass the viability reassessment - number of accessions with pending viability reassessment

${ }^{\mathrm{c}}$ The viability of the accessions cryopreserved in 2016 will be reassessed in 2017/2018 (after 1-2 yr in LN) 


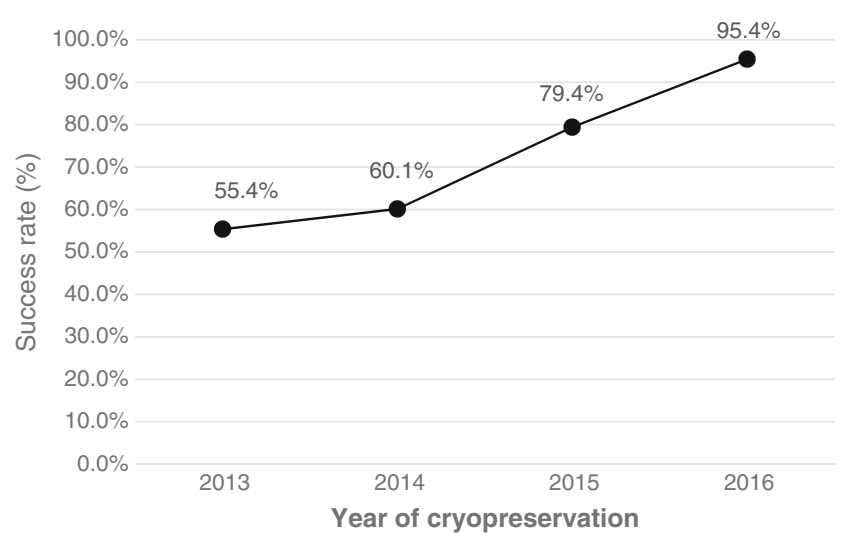

Figure 1. Success rate (\%) of potato cryopreservation at CIP (2013 to 2016). The success rate (\%) is expressed as the relationship between successfully cryopreserved and totally processed accessions. An accession is considered as successfully cryopreserved if it had a minimum recovery rate of $30 \%$ or higher (one single cryopreservation attempt) or 20-30\% (two independent cryopreservation attempts).

and recovering as described above with the seemingly minor change that the recovery cycle, 30 to $60 \mathrm{~d}$ post-thawing, was performed in $25 \times 150 \mathrm{~mm}$ instead of $13 \times 100 \mathrm{~mm}$ test tubes. Two $25 \times 150 \mathrm{~mm}$ test tubes per accession were used, placing a maximum of five shoot tips per test tube. Only samples that showed survival or recovery after $30 \mathrm{~d}$ were transferred to the test tubes (Fig. 2).

In total, the viability of 857 potato accessions from 2014 to 2015 was reassessed (Table 1). Data was analyzed with box plots and a two-sample $t$ test $(p<0.05)$ (Fig. 2). Additionally, the recovery rates of the vial with the central (median-valued vial) and maximum value of the original viability (based on 10 shoot tips, respectively) were compared with the recovery rate of the reassessed vial (based on 10 shoot tips) (Table 5).

Influence of the human factor on cryopreservation The survival and recovery rates of cryopreserved potato based on the eight different technicians conducting the procedure were compared using a group of 979 accessions cryopreserved in 2015 and 2016. Technician performance was measured based on routinely obtained survival and recovery rates of cryopreserved potatoes. Technician 7 was the most experienced technical staff member, who trained the other technicians (Tech 16 and Tech 8) (Fig. 3). Sample sizes ranged from 45 to 377 accessions per technician.

\section{Results}

Routine cryopreservation In 2016, a higher number of potato accessions (575 accessions) were successfully cryopreserved compared to previous years (2013: 113 accessions; 2014: 415 accessions; 2015: 442 accessions) (Table 1). The average recovery rates $(+\mathrm{LN})$ of the accessions cryopreserved in $2016(60.9 \%)$ and 2015 (59.6\%) were significantly higher than in the two prior years 2014 (53.3\%) and 2013 (50.2\%). Also, the average survival rate of the 2016 cryopreserved accessions $(71.5 \%)$ was higher compared to $2014(68.4 \%)$ and 2013 (66.8\%) (Fig. 4).

The cryopreserved material belonged primarily to the accessions of tetraploid taxa Solanum tuberosum subsp. andigenum (1126), followed by S. stenotomum subsp. stenotomum (122), S. tuberosum subsp. tuberosum (74), S. phureja (55), S. chaucha (48), and S. stenotomum subsp. goniocalyx (44). Comparisons among the material successfully cryopreserved were made to evaluate whether specific attributes such as taxonomic classification, ploidy level, or country of origin influenced success rates. Based on comparisons using the Tukey multiple comparison test $(p<0.05)$, $S$. tuberosum subsp. tuberosum showed a significantly higher average recovery rate of $64.2 \%$ than the taxa $S$. phureja (53.1\%), S. stenotomum subsp. goniocalyx (52.8\%), and S. stenotomum subsp. stenotomum (48.9\%). Solanum tuberosum subsp. andigenum showed a significantly higher average recovery rate of $58.9 \%$ than $S$. stenotomum subsp. stenotomum (48.9\%), but no significant differences were observed when compared with the other analyzed species and subspecies (Table 2).

A Tukey test was conducted to determine if ploidy level influenced the cryopreservation success rate. Tetraploid $(4 \times)$ accessions had a significantly higher average recovery rate $(58.9 \%)$ than diploid $(2 \times)$ accessions $(50.7 \%)$. No significant differences were observed in either survival or recovery rates between triploid $(3 \times)$ and tetraploid $(4 \times)$ accessions (Table 3 ). Geographic origin, defined as the country where the accession was collected, was also assessed to determine if this had an effect on cryopreservation success. Accessions from Chile had a significantly higher average recovery rate $(65.1 \%)$ than accessions from Peru (57.1\%). No statistically significant differences were observed between the average recovery rate of the accessions coming from Chile, Colombia, Ecuador, and Venezuela (Table 4).

An evaluation of the influence of staff technicians and their experience on the success of the cryopreservation process was also analyzed (Fig. 3). Technician (Tech) 4 showed a significantly higher average cryopreservation recovery rate of $67.5 \%$ compared to the remaining Techs (44.6-57.6\%). Tech 4 had $2 \mathrm{yr}$ of experience in the cryopreservation process and showed a significantly higher recovery rate compared to a technician with more than $20 \mathrm{yr}$ of experience (Tech 7). No significant differences were observed between the senior staff Tech 7 (69.4\%) and Tech 4 (76.9\%) in terms of the cryopreservation survival rates, but, both showed a significantly higher average cryopreservation survival rate than the other technicians. The average cryopreservation recovery and survival rates of Tech 4 , Tech 3, and Tech 8 were based on larger sample sizes of 377,171 , and 128 accessions, respectively. 

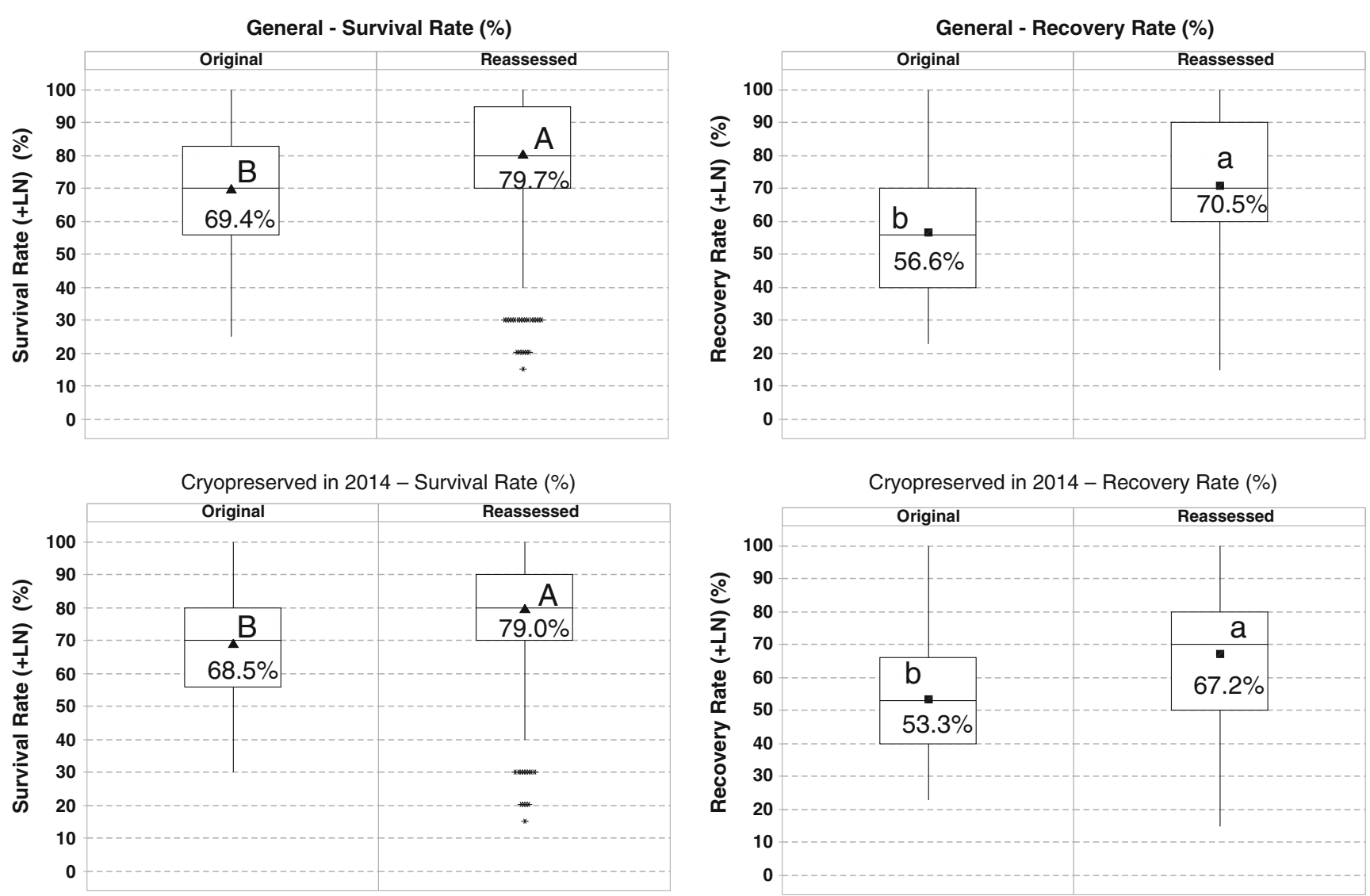

Cryopreserved in 2015 - Survival Rate (\%)

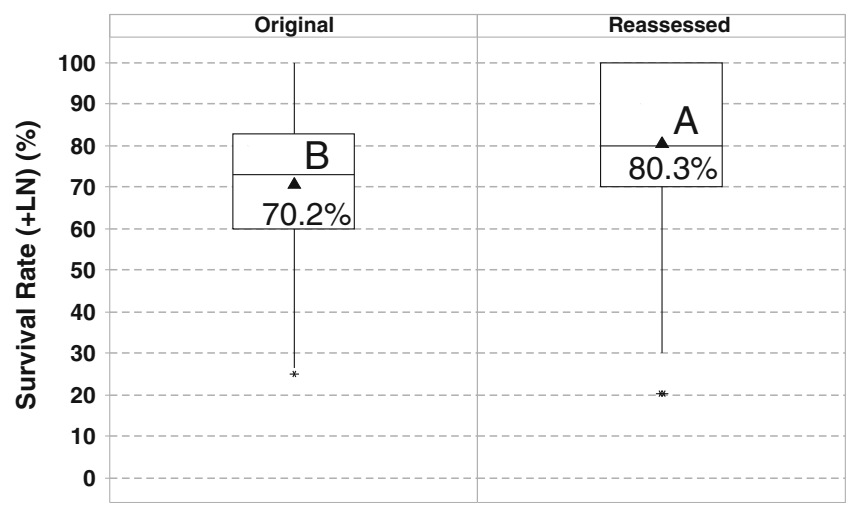

Figure 2. Box plot graphs of original and reassessed survival and recovery rates of 849 accessions that were successfully cryopreserved at CIP's cryobank in the years 2014-2015. Original and reassessed data are based on sample sizes of 30 and 10 shoot tips, respectively. Black triangle: mean of survival rate; black square: mean of recovery rate;

Viability reassessment Periodic viability reassessment of cryopreserved material is crucial to confirm the stability of viability over time, as is the case for seed collections. Viability reassessment after 1-2 yr is important to establish the functional QMS for cryopreservation and to identify potential problems or accessions with suboptimal viability at an early stage.

It was interesting to observe that the survival and recovery rates of the viability reassessment were significantly higher

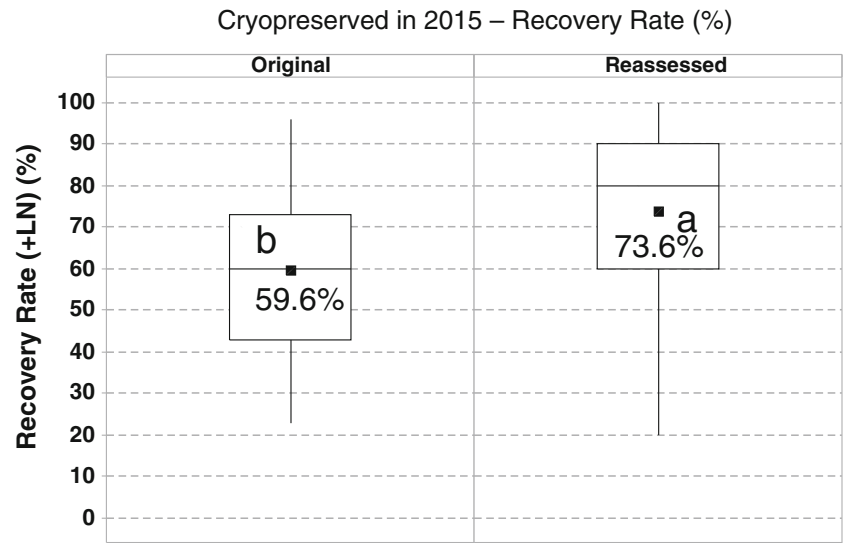

asterisks: outlier values. Different letters indicate significant differences for the two-sample $t$ test $(p<0.05)$. Statistical differences between survival rates are indicated with capital letters, and differences between recovery rates are indicated with lowercase letters. Mean values of survival and recovery rates are indicated within the box plot graphs.

$(p<0.05)$ than the original viability data. The mean values of the reassessed survival and recovery rates were 10.3 and $13.9 \%$ higher, respectively, than the original data (Fig. 2). The difference between the reassessed average survival and recovery rates of the 2015 material was $6.7 \%$, which is $4 \%$ lower than the original data $(10.6 \%)$. A similar tendency was observed for the 2014 material ( $\Delta$ reassessment $11.8 \% ; \Delta$ original $15.2 \%)$. Four of the 857 reassessed accessions $(<0.5 \%)$ showed signs of contamination (two vials were 


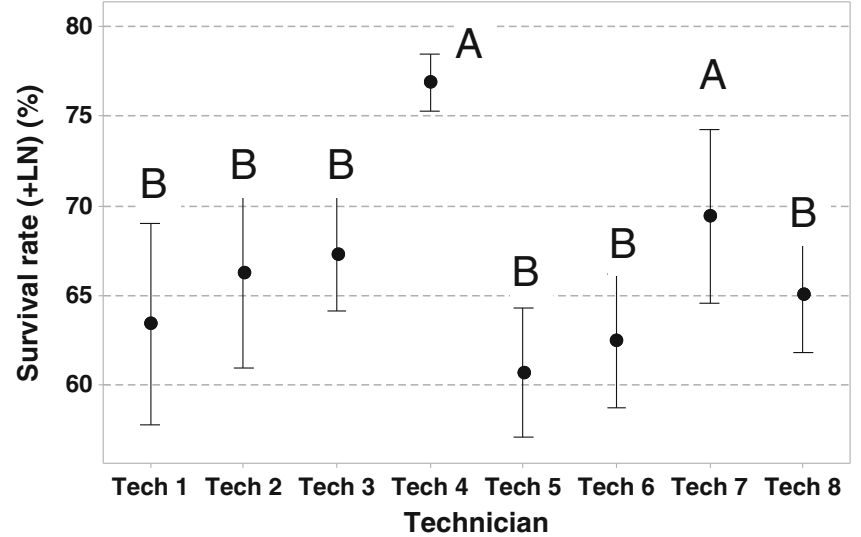

Figure 3. The survival and recovery rates of 979 potato accessions, routinely cryopreserved by eight different technicians (years 2015 to 2016). Tech 7 is the senior technical staff member, who trained all the other staff members (Tech 1-6 and Tech 8). Filled circle: median values.

tested), and thus, the accessions were discarded from the cryobank.

For 552 of 849 accessions (65\%), the reassessed vial showed a higher recovery rate than the median-valued vial of the original assessment (Table 5).

\section{Discussion}

During 2016, an increase in the post-thawing survival and recovery rates of cryopreserved potato accessions was observed. Specifically, in S. tuberosum subsp. tuberosum, a noteworthy increase in the average recovery rate from 59.0 to $64.2 \%$ was obtained (Vollmer et al. 2016). The continuous improvement of the survival, recovery $(+\mathrm{LN})$, and yearly

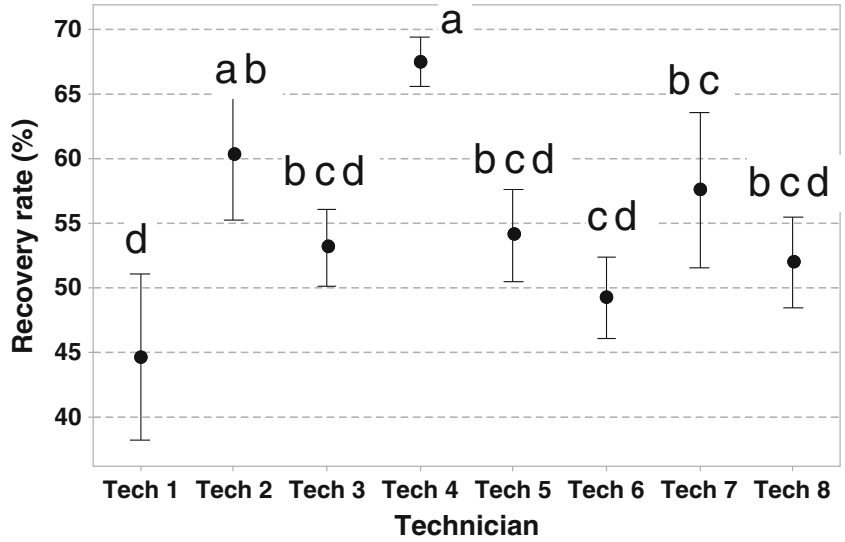

Different letters indicate significant differences for the Tukey test for the means $(p<0.05)$. Statistical differences between survival rates are indicated with capital letters, and differences between recovery rates are indicated with lowercase letters.

throughput rates in CIP's cryobank during the years 20132016 can be attributed to an increase in the technical abilities and experience of the research staff as no major changes in the protocol were made. Interestingly, the Institute of Plant Genetics and Crop Plant Research (IPK) in Germany reported the opposite effect in the cryopreservation of their potato genebank, with a decreasing trend for recovery of cryopreserved accessions with time (Keller et al. 2014).

Results of new and promising cryopreservation methods, like the dehydration (D)- and vitrification (V)-plate protocols, show high recovery rates of 70-93.3\% (13 accessions; D cryoplate) and $93.3-100 \%$ (16 accessions; V cryoplate) (Yamamoto et al. 2015; Valle et al. 2017), but the assessment of these methods on a larger scale (for example, $>500$ randomly selected accessions) has not yet been performed. It is

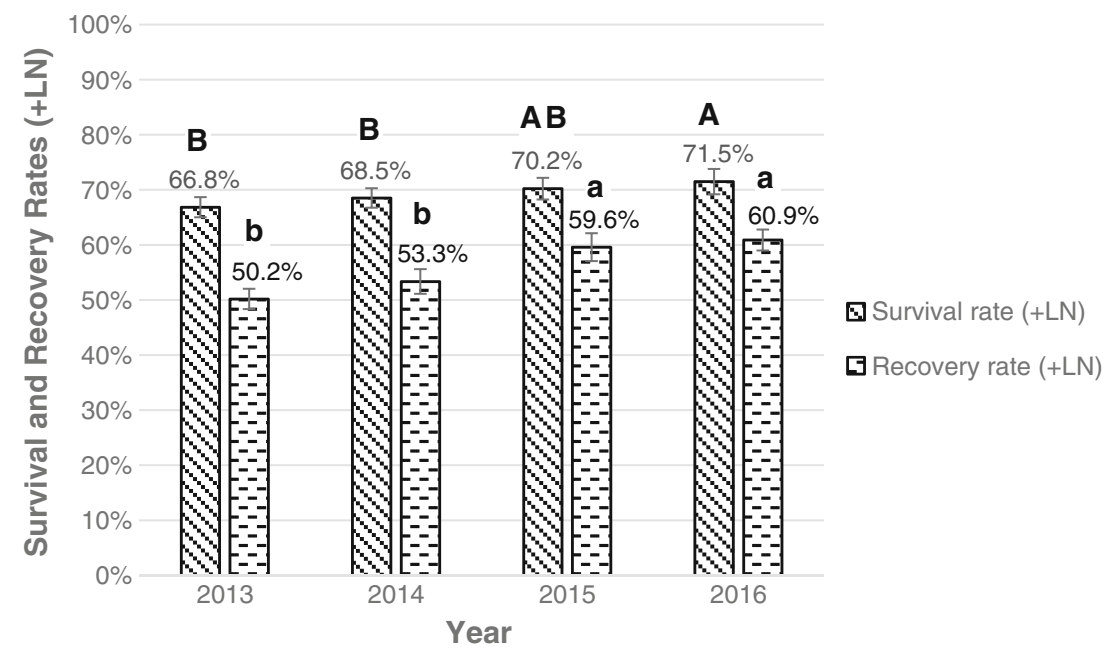

Figure 4. Average survival and recovery rates $(+\mathrm{LN})$ of 1533 potato accessions that were routinely cryopreserved at CIP between 2013 and 2016. Different letters indicate significant differences based on the Tukey multiple comparison test $(p<0.05)$. Statistical differences between

survival rates are indicated with capital letters, and differences between recovery rates are indicated with lowercase letters. Average survival and recovery rates per year are indicated above the graphs. Standard errors are indicated by bars. 
Table 2. Survival and recovery rates ( \pm standard error, SE) of 1533 potato accessions cryopreserved at CIP in the years 2013 to 2016. The accessions belong to seven species (based on Hawkes 1990) and four different ploidy levels $(2 \times, 3 \times, 4 \times$, and $5 \times)$. All accessions were cryopreserved with the PVS2-droplet cryopreservation method (LS 20 min, PVS2 $50 \mathrm{~min}$ on ice, RS $20 \mathrm{~min}$ ). Survival and complete plant recovery was assessed $60 \mathrm{~d}$ after thawing

\begin{tabular}{|c|c|c|c|}
\hline $\begin{array}{l}\text { Species/ } \\
\text { subspecies }\end{array}$ & $\begin{array}{l}\text { Number of } \\
\text { cryobanked } \\
\text { accessions }\end{array}$ & $\begin{array}{l}\text { Average survival } \\
\text { rate }(+\mathrm{LN}) \\
(\% \pm \mathrm{SE})^{(1)}\end{array}$ & $\begin{array}{l}\text { Average recovery } \\
\text { rate }(+\mathrm{LN}) \\
(\% \pm \mathrm{SE})^{(1)}\end{array}$ \\
\hline $\begin{array}{l}\text { Solanum } \\
\quad \text { tuberosum } \\
\text { subsp. } \\
\text { tuberosum }\end{array}$ & 74 & $75.7 \pm 2.3 \mathrm{~A}$ & $64.2 \pm 2.3 \mathrm{a}$ \\
\hline $\begin{array}{l}\text { Solanum } \\
\quad \text { tuberosum } \\
\quad \text { subsp. } \\
\text { andigenum }\end{array}$ & 1126 & $70.4 \pm 0.5 \mathrm{AB}$ & $58.9 \pm 0.5 \mathrm{ab}$ \\
\hline $\begin{array}{l}\text { Solanum } \\
\quad \times \text { chaucha }\end{array}$ & 48 & $67.4 \pm 2.5 \mathrm{AB}$ & $56.2 \pm 2.9 \mathrm{abc}$ \\
\hline $\begin{array}{l}\text { Solanum } \\
\quad \times \text { juzepczukii }{ }^{(2)}\end{array}$ & 11 & $65.9 \pm 4.0^{(2)}$ & $54.8 \pm 5.5^{(2)}$ \\
\hline Solanum phureja & 55 & $66.0 \pm 2.3 \mathrm{~B}$ & $53.1 \pm 2.5 \mathrm{bc}$ \\
\hline $\begin{array}{l}\text { Solanum } \\
\quad \text { stenotomum } \\
\text { subsp. } \\
\text { stenotomum }\end{array}$ & 122 & $66.9 \pm 1.5 \mathrm{~B}$ & $48.9 \pm 1.5 \mathrm{c}$ \\
\hline $\begin{array}{l}\text { Solanum } \\
\quad \text { stenotomum } \\
\text { subsp. } \\
\text { goniocalyx }\end{array}$ & 44 & $68.5 \pm 2.3 \mathrm{AB}$ & $52.8 \pm 2.6 \mathrm{bc}$ \\
\hline $\begin{array}{l}\text { Solanum } \\
\quad \times \text { ajanhuiri }^{(2)}\end{array}$ & 9 & $66.9 \pm 6.7^{(2)}$ & $51.1 \pm 5.7^{(2)}$ \\
\hline $\begin{array}{l}\text { Solanum } \\
\quad \times \text { curtilobum }^{(2)}\end{array}$ & 2 & $38.5 \pm 2.5^{(2)}$ & $32.0 \pm 2.0^{(2)}$ \\
\hline $\begin{array}{l}\text { Solanum sp. } \\
\text { (hybrids) }\end{array}$ & 42 & $69.3 \pm 2.3 \mathrm{AB}$ & $57.7 \pm 2.2 \mathrm{abc}$ \\
\hline Mean & & $70.0 \pm 0.4$ & $57.7 \pm 0.5$ \\
\hline
\end{tabular}

(1) Different letters indicate significant differences based on the Tukey multiple comparison test $(p<0.05)$. Statistical differences between survival rates are indicated with capital letters, and differences between recovery rates are indicated with lowercase letters

${ }^{(2)}$ Solanum $\times$ juzepczukii, Solanum $\times$ ajanhuiri, and Solanum $\times$ curtilobum were excluded from the statistical analysis, as they contained a low sample number of $2-11$ accessions per species

also important to highlight that CIP's potato cryobank exclusively conserves landraces, while other collections contain higher quantities of improved potato varieties or breeding material, which tend to be less variable and have a narrower genetic base than landraces. The intra-specific recovery rates reported in the present work are also based on hundreds of accessions and, therefore, are difficult to compare to more specific protocols using a very limited number of accessions. Practicality of the cryomethod, yearly throughput rate per person, and strict viability assessment criteria (complete plant recovery) are all important factors that need to be considered for any large-scale cryobank operation.
Table 3. Survival and recovery rates ( \pm standard error, SE) of 1329 cryopreserved potato accessions classified by its ploidy level $(2 \times, 3 \times$, $4 \times$, and $5 \times$ ). Ploidy level was determined by flow cytometry (BD Accuri C6). Accessions with missing ploidy data were excluded from the analysis. Accessions were cryopreserved with the PVS2-droplet cryopreservation method (LS $20 \mathrm{~min}$, PVS2 $50 \mathrm{~min}$ on ice, RS $20 \mathrm{~min}$ ). Survival and complete plant recovery was assessed $60 \mathrm{~d}$ after thawing

\begin{tabular}{llll}
\hline $\begin{array}{l}\text { Ploidy } \\
\text { level }\end{array}$ & $\begin{array}{l}\text { Number of } \\
\text { cryopreserved } \\
\text { accessions }\end{array}$ & $\begin{array}{l}\text { Average survival } \\
\text { rate }(+\mathrm{LN}) \\
(\% \pm \mathrm{SE})^{(1)}\end{array}$ & $\begin{array}{l}\text { Average recovery } \\
\text { rate }(+\mathrm{LN}) \\
(\% \pm \mathrm{SE})^{(1)}\end{array}$ \\
\hline $2 \times$ & 200 & $66.9 \pm 1.2 \mathrm{~B}$ & $50.7 \pm 1.2 \mathrm{~b}$ \\
$3 \times$ & 95 & $67.6 \pm 1.5 \mathrm{AB}$ & $54.6 \pm 1.9 \mathrm{ab}$ \\
$4 \times$ & 1032 & $70.6 \pm 0.5 \mathrm{~A}$ & $58.9 \pm 0.6 \mathrm{a}$ \\
$5 \times^{(2)}$ & $2^{(2)}$ & $38.5 \pm 2.5^{(2)}$ & $32.0 \pm 2.0^{(2)}$ \\
\hline
\end{tabular}

(1) Different letters indicate significant differences based on the Tukey multiple comparison test $(p<0.05)$. Statistical differences between survival rates are indicated with capital letters, and differences between recovery rates are indicated with lowercase letters

(2) The pentaploid accessions were excluded from the statistical analysis, because of a low sample number $(n=2)$

In CIP's cryobank, higher average recovery rates $(+\mathrm{LN})$ were observed for the $S$. tuberosum subsp. tuberosum and subsp. andigenum (64.2 and 58.9\%), S. chaucha (56.2\%), and $S$. ×juzepczukii (54.8\%), while the diploid species showed lower average recovery rates ranging from 48.9 to $53.1 \%$ (Table 2). A direct relationship between ploidy level and cryoresponse could be analyzed, but needs to be further investigated. S. stenotomum subsp. stenotomum showed a high differential of $>18 \%$ between the average survival and recovery rates. The pentaploid $S$. curtilobum had a low average recovery rate of $32.0 \%$, but this is based on a very small sample size ( 2 accessions) and it cannot be concluded that it is a characteristic of this particular ploidy level. The optimization of the cryopreservation protocols for the diploid S. stenotomum subsp. stenotomum and the pentaploid Solanum $\times$ curtilobum could be considered for future research projects.

As $98 \%$ of the Chilean accessions belong to the tetraploid S. tuberosum subsp. tuberosum, and showed a significantly higher recovery rate than the accessions coming from other countries, there could be a correlation between the specific ploidy or genetic composition of tuberosum subspecies. The Chilean accessions were originally obtained from the extreme south (between the latitude of -42.66 and $44.37^{\circ} \mathrm{S}$; data not shown). However, it is important to note that 69 of the 70 cryopreserved Chilean accessions belong to a single taxon, S. tuberosum subsp. tuberosum, which as noted above had significantly higher recovery rates that may account for this seemingly geographical difference. The viability reassessment of the 2014-2015 cryopreserved accessions confirmed a minimum recovery rate of $20 \%$ for $99 \%$ of the accessions (based on one single vial). The data of the 849 successfully reassessed potato accessions showed a higher average 
Table 4. Survival and recovery rates ( \pm standard error) of 1533 cryopreserved potato accessions from 2013 to 2016, classified per country of origin. All accessions were cryopreserved with the PVS2droplet cryopreservation method (LS $20 \mathrm{~min}$, PVS2 $50 \mathrm{~min}$ on ice, RS $20 \mathrm{~min}$ ). Survival and complete plant recovery were assessed $60 \mathrm{~d}$ after thawing

\begin{tabular}{llll}
\hline $\begin{array}{l}\text { Country of } \\
\text { origin }\end{array}$ & $\begin{array}{l}\text { Number of } \\
\text { cryopreserved } \\
\text { accessions }\end{array}$ & $\begin{array}{l}\text { Average post }+\mathrm{LN} \\
\text { survival rate } \\
(\% \pm \mathrm{SE})^{(1)}\end{array}$ & $\begin{array}{l}\text { Average post }+\mathrm{LN} \\
\text { recovery rate } \\
(\% \pm \mathrm{SE})^{(1)}\end{array}$ \\
\hline Argentina & 27 & $68.0 \pm 2.9 \mathrm{AB}$ & $57.5 \pm 3.1 \mathrm{ab}$ \\
Bangladesh $^{(2)}$ & 2 & $69.5 \pm 6.5$ & $66.0 \pm 10.0$ \\
Bolivia $^{(2)}$ & 230 & $71.1 \pm 1.1 \mathrm{AB}$ & $57.7 \pm 1.2 \mathrm{~b}$ \\
Bhutan $^{(2)}$ & 1 & 70.0 & 56.0 \\
Chile $_{\text {Colombia }}$ & 70 & $76.1 \pm 2.3 \mathrm{~A}$ & $65.1 \pm 2.3 \mathrm{a}$ \\
Costa Rica $^{(2)}$ & 1 & $71.8 \pm 1.7 \mathrm{AB}$ & $59.5 \pm 1.9 \mathrm{ab}$ \\
Ecuador & 65 & 66.0 & 56.0 \\
Guatemala $^{(2)}$ & 8 & $67.0 \pm 1.9 \mathrm{~B}$ & $56.0 \pm 2.3 \mathrm{ab}$ \\
Mexico $^{(2)}$ & 6 & $66.9 \pm 5.4$ & $59.4 \pm 4.0$ \\
Netherlands $^{(2)}$ & 1 & $76.8 \pm 6.6$ & $65.7 \pm 7.9$ \\
Peru $_{\text {Russia }}^{(2)}$ & 990 & 76.0 & 56.0 \\
Venezuela $^{(23}$ & 9 & $69.4 \pm 0.5 \mathrm{~B}$ & $57.1 \pm 0.6 \mathrm{~b}$ \\
\hline
\end{tabular}

${ }^{(1)}$ Different letters indicate significant differences based on the Tukey multiple comparison test $(p<0.05)$. Statistical differences between survival rates are indicated with capital letters, and differences between recovery rates are indicated with lowercase letters

${ }^{(2)}$ Countries with low sample size of $<9$ accessions per country were excluded from the statistical analysis

recovery rate of $70.5 \%$ compared to the original rate of $56.6 \%$ (an average differential of $13.9 \%$ ). Finally, $79 \%$ of the reassessed accessions showed an equal or higher recovery rate compared to the median-valued vials of the routine data (Table 5)

The 30-60 d post-thaw period of the 2014-2015 reassessment was done in wider $25 \times 150 \mathrm{~mm}$ test tubes, with more plants per tube, while the 2013 material was reassessed in $13 \times 100$ test tubes with one plant per tube. The 2013 material (109 accessions) had an original average recovery rate of $50.3 \%$, and for its viability reassessment, a recovery rate of $55.1 \%$ was reported (Vollmer et al. 2016). Based on the observation that the differential for the 2014-2015 material was nearly three times higher than for the 2013 material, it is possible that the dimensions of the test tubes used or the number of plants per test tube influenced the recovery rate. It is also possible that the increased expertise of the cryobank staff at the time of reassessment (2014/15 material) was a factor in the higher recovery rate. This hypothesis would explain the continuously increased success rate for routine cryopreservation from 2013 to 2016 (Fig. 1). Further research is required to assess the influence of the storage vessel and the technical
Table 5. Comparison between the vials with the highest and middle recovery rates of the three routinely assessed vials and the recovery rates of the reassessed vial ( 849 accessions). In this case, recovery rates of the routinely evaluated and reassessed vials were both based on a sample size of 10 shoot tips. The table shows the number of accessions (total 849 accessions); the reassessment showed lower, equal, or higher recovery rates compared to one single vial (median or maximum value) of the original routine data

\begin{tabular}{|c|c|c|}
\hline Description & $\begin{array}{l}\text { Comparison of } \\
\text { recovery } \\
\text { rates }\end{array}$ & $\begin{array}{l}\text { Number of } \\
\text { accessions }\end{array}$ \\
\hline \multirow{3}{*}{$\begin{array}{l}\text { Compared to the } \\
\text { middle-valued } \\
\text { vials }{ }^{\mathrm{a}} \text { of the routine } \\
\text { recovery rate }\end{array}$} & Routine $>$ reassessment & 175 \\
\hline & Routine $=$ reassessment & 122 \\
\hline & Routine $<$ reassessment & 552 \\
\hline \multirow{3}{*}{$\begin{array}{l}\text { Compared to the } \\
\text { highest-valued } \\
\text { vials }{ }^{\mathrm{b}} \text { of the routine } \\
\text { recovery rate }\end{array}$} & Routine $>$ reassessment & 336 \\
\hline & Routine $=$ reassessment & 153 \\
\hline & Routine $<$ reassessment & 360 \\
\hline
\end{tabular}

${ }^{a}$ The middle-valued vial (or median-valued vial) of each accession is that single vial of the three routinely assessed vials that had the central value of recovery

${ }^{\mathrm{b}}$ The highest-valued vial of each accession is that single vial of the three routinely assessed vials that had the highest value of recovery

staff's experience on the post-thawing recovery rate in cryopreservation.

The influence of the human factor on the survival and recovery rates has also been shown. Although Tech 7 had more than $20 \mathrm{yr}$ of practical experience in cryopreservation, has cryopreserved thousands of accessions, and co-developed CIP's cryomethod, Tech 4 apparently had found a way to increase the recovery rate substantially with putatively improved excision or sample handling. The PVS2-droplet method is a multi-step process, which requires fine motor skills in many steps, like shoot tip excision, treatment of samples with LS and PVS2, forming the PVS2 droplet, placing the PVS2 droplet (with 10 shoot tips) on a small aluminum strip, and plunging it into LN. Minor changes in sample handling could have a major influence on the recovery results. The performance of Tech 4 is currently being analyzed systematically to identify the critical step or steps that have led to the increased cryopreservation process improvement.

\section{Conclusions}

The efficiency of CIP's cryomethod was confirmed with a high number (1533) of potato landraces belonging to seven different species. In 2016, 95\% of the processed potato accessions did accomplish CIP's minimum viability standards ( $\geq 20 \%$ viability). In a viability reassessment of the 2014 2015 cryopreserved accessions, $99 \%$ of the cryopreserved accessions fulfilled the minimum viability standards, confirming 
the robustness of the previously established quality management system. A potential for protocol improvement by conducting a systematical review of sample handling procedures has been identified, based on the outstanding performance of one specific technician.

Acknowledgements We express our sincere gratitude and thanks to the Global Crop Diversity Trust (GCDT) and the Genebank CGIAR Research Program for funding this work.

We also want to thank the following technical staff members for their continuous effort and commitment with CIP's potato cryobank: Maria Torres, Juan Carlos Sanchez, Andres Montoya, and Tjark Monteblanco.

Open Access This article is distributed under the terms of the Creative Commons Attribution 4.0 International License (http:// creativecommons.org/licenses/by/4.0/), which permits unrestricted use, distribution, and reproduction in any medium, provided you give appropriate credit to the original author(s) and the source, provide a link to the Creative Commons license, and indicate if changes were made.

\section{References}

Bajaj YPS (1978) Tuberization in potato plants regenerated from freezepreserved meristems. Crop Improv 5:137-141

Bajaj YPS (1981) Regeneration of plants from potato meristems freezepreserved for 24 months. Euphytica 30:141-145

Doležel J, Binarová P, Lucretti S (1989) Analysis of nuclear DNA content in plant cells by flow cytometry. Biol Plant 31:113-120

Food and Agriculture Organization of the United Nations FAO (2009) International treaty on plant genetic resources for food and agriculture. Cited 11 July 2017. ftp://ftp.fao.org/docrep/fao/011/i0510e/ i0510e.pdf

Golmirzaie A, Panta A (2000) Advances in potato cryopreservation at CIP. In: Engelmann F, Takagi H (eds) Cryopreservation of tropical plant germplasm: current research progress and application, JIRCAS, Tsukuba/IPGRI, Rome, pp 250-254

Grout BW, Henshaw GG (1978) Freeze-preservation of potato shoot-tip cultures. Ann Bot 42:1227-1229

Hawkes JG (1990) The potato: evolution, biodiversity, and genetic resources. Belhaven Press

Keller ERJ, Senula A, Grübe M, Diekmann K, Dehmer HJ (2014) Fifteen years of cryopreservation in the IPK Genebank- experience, conclusions and outlook. Acta Hortic 1039:249-264
Murashige T, Skoog F (1962) A revised medium for rapid growth and bio assays with tobacco tissue cultures. Physiol Plant 15:473-497

Orillo M and Bonierbale M (2009) Biología reproductive y citogenética de la papa. Centro Internacional de la Papa (CIP). Manual técnico. 22 p. Lima (Perú)

Panis B, Piette B, Swennen R (2005) Droplet vitrification of apical meristems: a cryopreservation protocol applicable to all Musaceae. Plant Sci 168:45-55

Panta A, Panis B, Ynouye C, Swennen R, Roca W, Tay D, Ellis D (2015) Improved cryopreservation method for the long-term conservation of the world potato germplasm collection. Plant Cell Tissue Organ Cult 120:117-125

Pritchard HW (2016) Priority science for the preservation of priority crops. Indian J Plant Genet Resour 29:297-297

Sakai A, Kobayashi S, Oiyama I (1990) Cryopreservation of nucellar cells of navel orange (Citrus sinensis Osb. var. brasiliensis Tanaka) by vitrification. Plant Cell Rep 9:30-33

Schäfer-Menuhr A, Schumacher HM, Mix-Wagner G (1994) Langzeitlagerung alter Kartoffelsorten durch Kryokonservierung der Meristeme in flüssigem Stickstoff. Landbauforschung Völkenrode 44:301-313

Schäfer-Menuhr A, Schumacher HM, Mix-Wagner G (1997) Long-term storage of old potato varieties by cryopreservation of shoot-tips in liquid nitrogen. Plant Genet Resour Newsl 111:19-24

Towill LE (1981) Survival at low temperatures of shoot-tips from cultivars of Solanum tuberosum group tuberosum. CryoLetters 2:373382

Towill LE (1983) Improved survival after cryogenic exposure of shoot tips derived from in vitro plantlet cultures of potato. Cryobiology 20 : $567-573$

Towill LE (1984) Survival at ultra-low temperatures of shoot tips from Solanum tuberosum groups andigena, phureja, stenotomum, tuberosum, and other tuber-bearing Solanum species. CryoLetters 5:319-326

Valle M, Villalobus OF, Castillo CM, Cruz EJ, López HA, Yamamoto S, Watanabe K, Niino T (2017) Improvement of the D cryo-plate protocol applied to practical cryopreservation of in vitro grown potato shoot tips. Horticulture J86:222-228

Vollmer R, Villagaray R, Egusquiza V, Espirilla J, Garcia M, Torres A, Rojas E, Panta A, Barkley NA, Ellis D (2016) The potato cryobank at the International Potato Center (CIP): a model for long-term conservation of clonal plant genetic resources collections of the future. CryoLetters 37:318-329

Yamamoto S, Wunna RT, Valle Arizaga M, Fukui K, Cruz Gutierrez EJ, Castillo Martinez CR, Watanabe K, Niino T (2015) The aluminum cryo-plate increases efficiency of cryopreservation protocols for potato shoot tips. Am J Potato Res 92:250-257 